\title{
Implementation and effectiveness of the Stress Check Program, a national program to monitor and control workplace psychosocial factors in Japan: a systematic review. Translated secondary publication
}

Stress Check Program

Akizumi Tsutsumi

Department of Public Health, Kitasato University School of Medicine, Sagamihara, Japan

Natsu Sasaki, Yu Komase and Kazuhiro Watanabe

Department of Mental Health, Graduate School of Medicine, The University of Tokyo, Bunkyo-ku, Japan

Akiomi Inoue

Department of Public Health, Kitasato University School of Medicine, Sagamihara, Japan, and

Kotaro Imamura and Norito Kawakami

Department of Mental Health, Graduate School of Medicine, The University of Tokyo, Bunkyo-ku, Japan

(C) Akizumi Tsutsumi, Natsu Sasaki, Yu Komase, Kazuhiro Watanabe, Akiomi Inoue, Kotaro Imamura and Norito Kawakami. Published by Emerald Publishing Limited. This article is published under the Creative Commons Attribution (CC BY 4.0) licence. Anyone may reproduce, distribute, translate and create derivative works of this article (for both commercial and non-commercial purposes), subject to full attribution to the original publication and authors. The full terms of this licence may be seen at http:// creativecommons.org/licences/by/4.0/legalcode.

This paper was published in Occupational Health Review 2019; 32: 65-81 in Japanese. With the permission of the editorial boards for Occupational Health Review and International Journal of Workplace Health Management, the paper was translated into English for publication. According to the reviewer's suggestion, the original paper was revised by adding some background and contextual information of the Japanese Stress Check Program for the international readers' understandings.

Funding: The present study was supported by Ministry of Health, Labour and Welfare, Japan (Industrial disease Clinical Research Grants [Grant Numbers, 180701-01 and 190501-01]).

Author contributions: The authors' contributions were as follows. Conception and design of the study: N.K., K.W., K.I. and A.T. Data collection and processing: N.S. and Y.K. Interpretation of data: N.S., Y.K., K.W., A.I., K.I. and A.T. Drafting the manuscript: N.S., Y.K., K.W., A.I., K.I., N.K. and A.T. Translation and revision: A.T. All authors have read and agreed to the published version of the manuscript.

Conflicts of interest. The authors declare no conflict of interest.

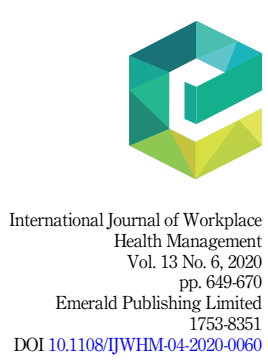


IJWHM 13,6

\begin{abstract}
Purpose - The purpose of this paper is to conduct a comprehensive review on the implementation and the effect of Japan's Stress Check Program, a national program to monitor and control workplace psychosocial factors that was initiated in December 2015.

Design/methodology/approach - We comprehensively reviewed articles published in Japanese and English, assessed the performance of the Stress Check Program and summarized future challenges. We also discussed the implications for practice.

Findings - The available literature presented a scientific basis for the efficiency and validity of predictions using the Brief Job Stress Questionnaire, which is the instrument recommended to screen workers with high stress in the program. No study has verified the effect of the program on workers' mental health by using group analysis of stress check results. There is room for improvement in tools that contribute to identifying workers with high stress and in measures for improving the work environment. The Stress Check Program contrasts with risk management of psychosocial factors at work, widely adopted in European countries as a strategy for improving workers' mental health by focussing on the psychosocial work environment.

Practical implications - Although the effectiveness of the Japanese program needs further evaluation, future developments of the program would provide insight for national policies on psychosocial risks/ psychosocial stress at work.
\end{abstract}

Originality/value - This paper is the first systematic review on the implementation and effects of Japan's Stress Check Program.

Keywords The stress check program, Brief job stress questionnaire, Occupational health system, Work environment improvement, Japan

Paper type Literature review

\title{
Introduction
}

Workers' mental health has been one of the biggest issues in Japan as is often the case in many other developed countries. As of 2014, a total of 1,456 claims were submitted requesting worker compensation for work-related mental disorders, and among these, 213 were suiciderelated. The number of claims for mental disorders had steadily increased almost five times during the previous 14 years. Japanese government came up with several remedies to address the growing problem of work-related mental disorders, including the amendments of Industrial Health and Safety Law and the release of guidelines to enhance effectiveness of the law. In sheer numbers of claims requesting compensation, however, it appeared that the remedies had only limited effects in improving workers' mental health. In 2014, this law was extended to include a Stress Check Program - the first mandated policy in the history of mental health in workplaces in Japan (Kawakami and Tsutsumi, 2016; Tsutsumi, 2016).

The Stress Check Program requires enterprises to implement an annual test (stress check) to gain understanding of the psychological burdens placed on their workers. Enterprises with fewer than 50 workers (small-scale enterprises) are only obligated to make reasonable efforts in this regard. Currently, the Stress Check Program is implemented in two ways. First, following preparation for implementation, a stress check is performed for all workers within an enterprise, and each worker is notified of their results. Based on these results, an interview with a physician is offered for those under high levels of stress (mandatory). Second, personal results are summarized and analysed for groups of a certain size, and group analysis used to improve the work environment (referred to as "reasonable efforts"). The Stress Check Program is the primary preventative measure for mental health issues among workers in Japan. Specifically, key functions of the Stress Check Program are: building awareness of workers' stress; providing support for self-care and improvement of the work environment based on test results. The stress checks mean that workers under high stress can be identified, including those who require professional support; this allows for secondary preventative measures to identify and respond to mental health issues (regarded as secondary objectives).

The Stress Check Program is part of a series of measures for workplace mental health in Japan (Kawakami and Tsutsumi, 2016; Tsutsumi, 2016). These measures must be enacted holistically to ensure maximum returns from implementation of the Stress Check Program. However, verifying evidence from individual activities within the Stress Check 
Program will be useful to inform efforts to further improve the program. These activities include: verifying test tools to identify high level of stress (the recommended tool is the Brief Job Stress Questionnaire [BJSQ]); implementing a routine survey for workers to reduce mental health risks through sharing results with each worker; screening for workers under high levels of stress to prevent mental health issues through interviews with physicians and reduction in psychological stress responses by improving work environments based on group analysis (including education for managers and supervisors) (Tsutsumi et al., 2018).

We comprehensively reviewed articles published in Japanese and English that focussed on the implementation and effects of the Stress Check Program, assessed the performance of the Stress Check Program for the first three years after initiation and summarized future challenges. The present study is the first systematic review focussed on the implementation and effects of the Stress Check Program. In this review, we examined the evidence on: (1) implementation of the Stress Check Program, (2) utility and validity of tools for stress checks and (3) effects of the Stress Check Program. We also discussed what the relevance of the Stress Check Program as implemented in Japan is to other countries, by comparing the policy and the components of the program with the trends in the management of psychosocial factors at work according to the policies and guidelines of international bodies and other countries. This evaluation and recent development of the national program may provide useful information for international readers who are interested in national policies on psychosocial risks/psychosocial stress in the workplace.

\section{Methods}

A search of Japanese language papers was performed using Ichushi Web (Japan Medial Abstracts Society) on 17 April 2019. Papers published in English were searched using MEDLINE (PubMed) on 27 March 2019. The target publication dates were within five years before initiation of the present study (2019), giving a start date of 1 January 2014. Japanese language papers were searched using the key search term "sutoresuchekkuseido" (stress check program), with types of papers limited to original articles and case reports using an Ichushi web filter function. English language papers were searched using the formula "((stress AND check) OR stress-check) AND Japan*." Titles, abstracts and full texts of returned papers were read by the authors and papers that met the following criteria were included. Eligibility criteria for Japanese language papers were as follows: (1) published in Japanese; (2) covered legislated content of the Stress Check Program (content in accordance with the Stress Check Program for those that used data before the legislation); (3) included stress checks as content and used a questionnaire that measured job stressors, stress responses and social support (program requirement) and (4) were not review articles, conference abstracts, commissioned reports, or papers not peer-reviewed. Eligibility criteria for English language papers were as follows: (1) published in English; (2) conducted after the introduction of the Stress Check Program; (3) focussed on the implementation, impact or challenges of the Stress Check Program or on the scientific bases for the questionnaire used for the program, and based on quantitative or qualitative data and (4) were peer-reviewed. In cases where it was difficult to determine whether a paper was related to the legislated Stress Check Program, all of the present authors made a consensus judgement on whether to include or exclude that paper. Included papers were summarized based on: (1) implementation of the Stress Check Program; (2) utility and validity of Stress Check tools and (3) effects of the Stress Check Program.

\section{Results}

The literature search identified 114 papers from the two databases: 60 Japanese language papers and 54 English language papers, with 18 papers finally included in this review (Figure 1). Of the 60 Japanese language papers, we excluded: papers written in English
Stress Check Program 
IJWHM 13,6

\section{2}

Figure 1.

PRISMA flow diagram

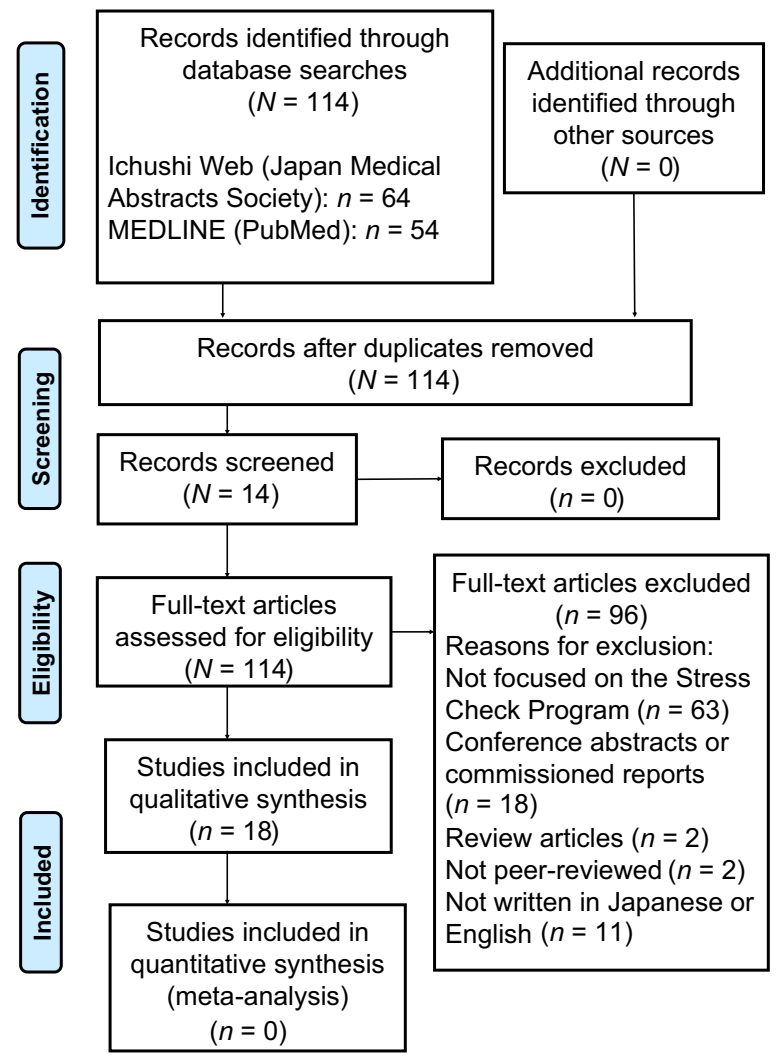

$(n=5)$; papers with inconsistent content $(n=18)$, including unrelated content $(n=12)$, preliminary tests before implementation of the program $(n=2)$ and studies without a questionnaire that measured job stressors, stress responses and social support $(n=4)$; conference abstracts $(n=12)$; commissioned reports $(n=6)$; papers that were not peerreviewed $(n=2)$ and reviews $(n=2)$. This left 15 Japanese language papers for inclusion in our review. Of the 54 English language papers, we excluded papers written in Japanese $(n=6)$ and papers with inconsistent content $(n=45)$, including those with unrelated content $(n=42)$ and reviews without data $(n=3)$. Finally, three English language papers were included in this review.

\section{Implementation of the stress check program}

Among the 18 papers included in this review, nine examined the implementation of the Stress Check Program (Table 1). Of these nine papers (including duplicates), three papers reported on the implementation rate of the Stress Check Program, six on the examination rate of the Stress Check Program, five on the prevalence of those under high levels of stress, two on the implementation rate of interviews with physicians and two on group analysis and implementation rate of improvements in the workplace environment. In this paper, we used the term "implementation rate", to refer to the proportion of enterprises that actually implemented the Stress Check Program or parts of the program (e.g. physician interview and 


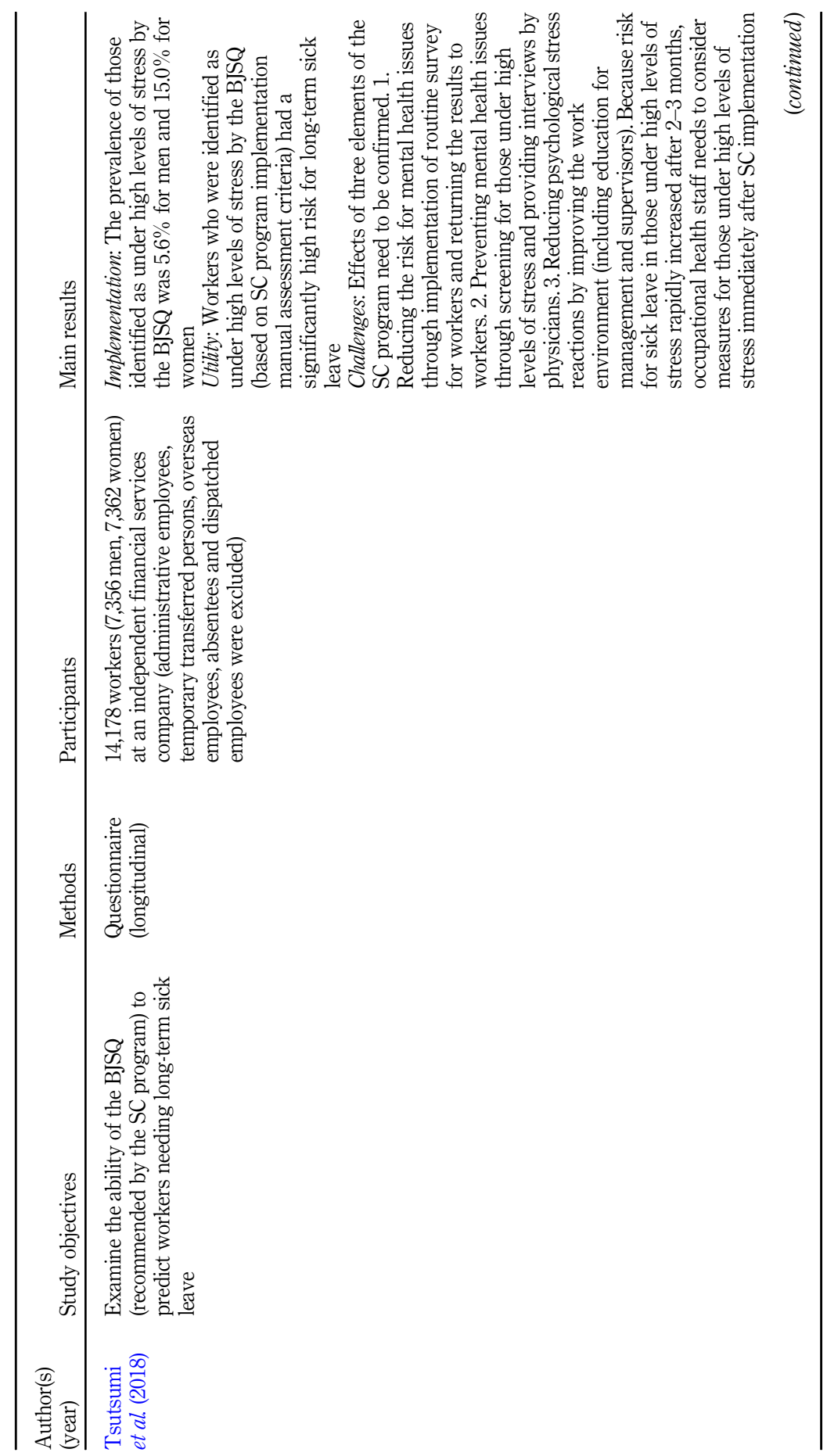

Stress Check

Program

653

Table 1.

Implementation and effects of the Stress Check Program: literature incorporated in this systematic review (18 papers) 


\section{IJWHM \\ 13,6}

654

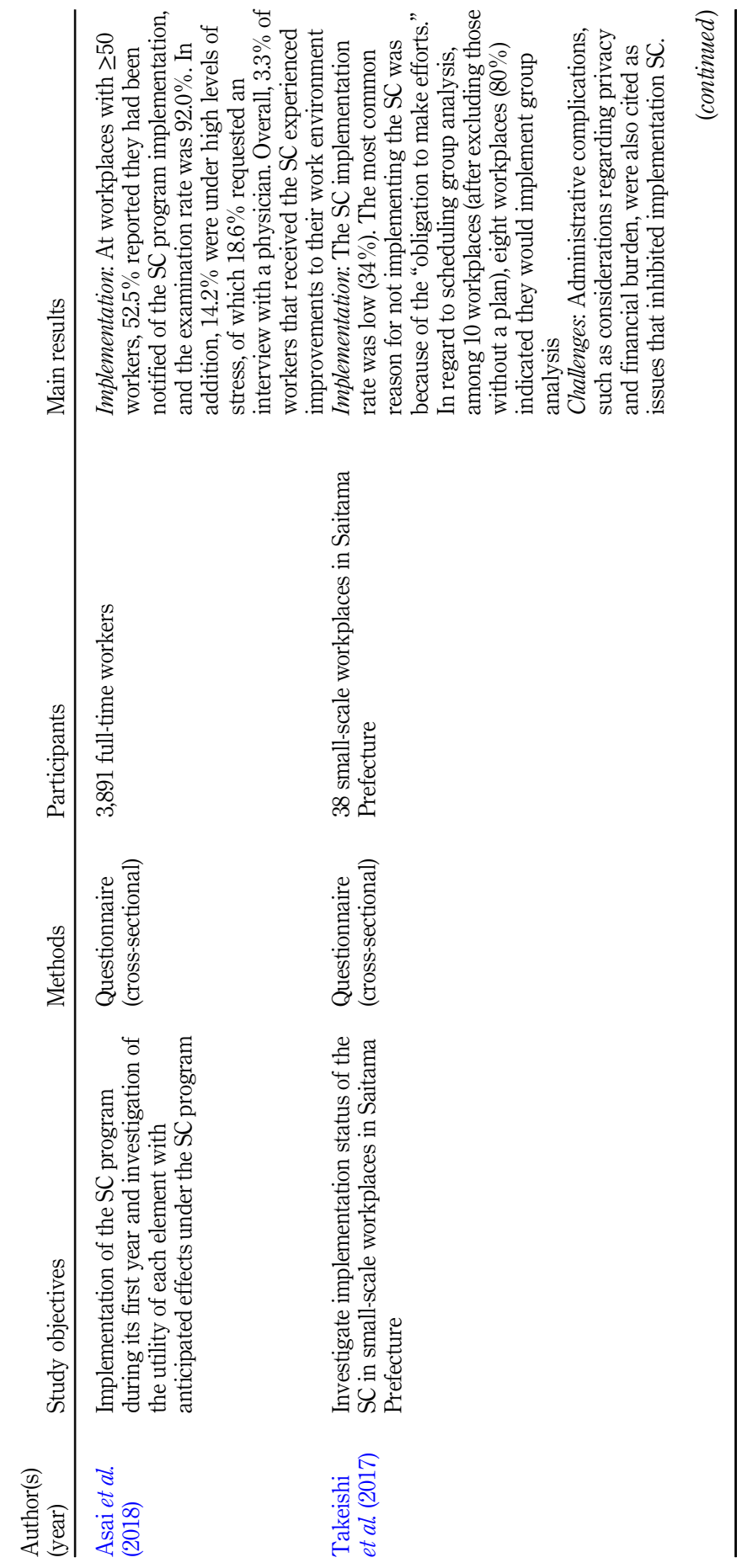




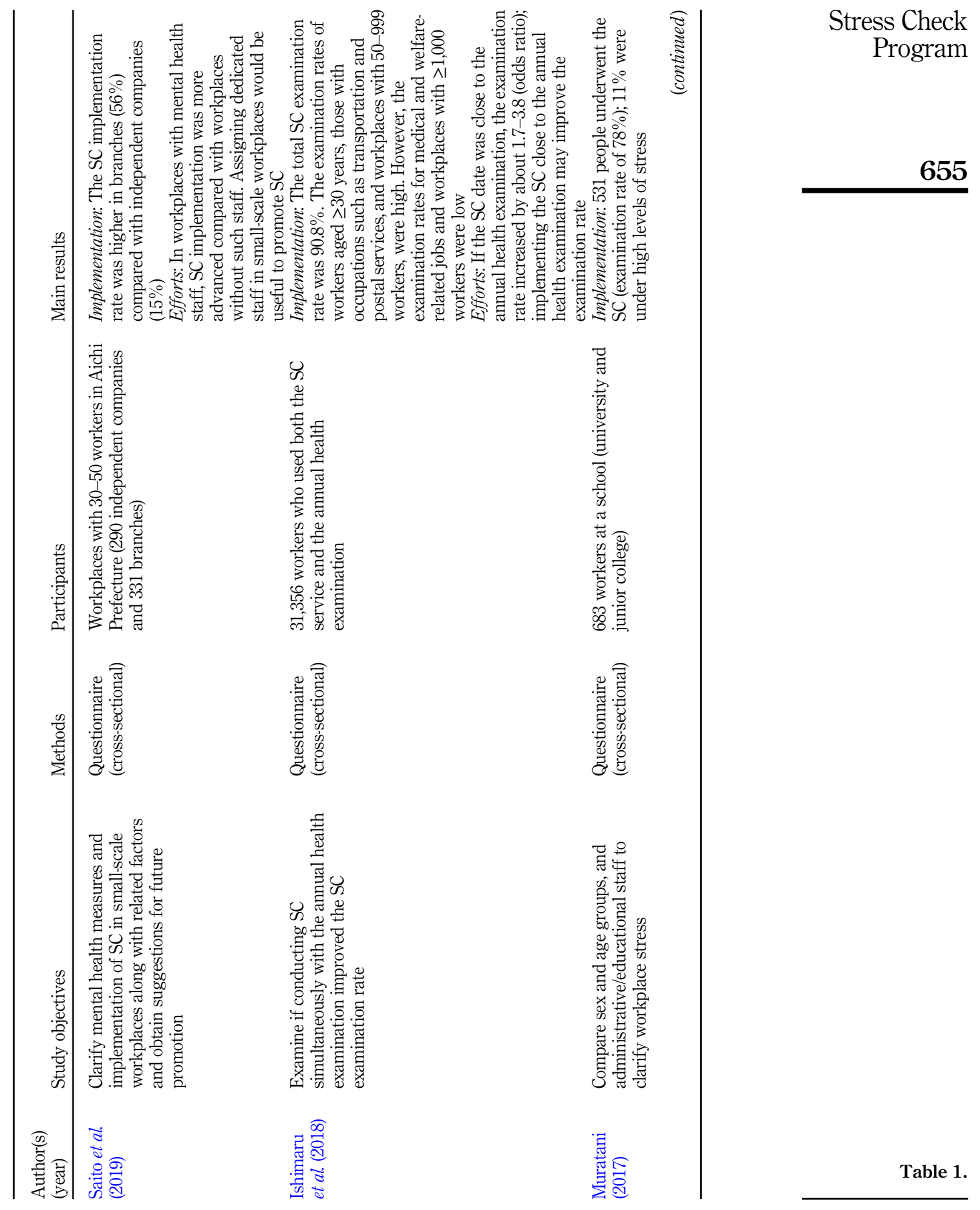


IJWHM
13,6

656

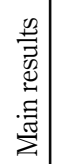

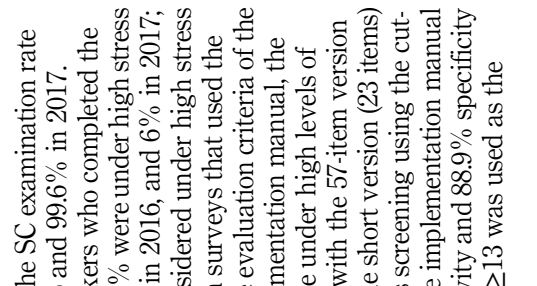

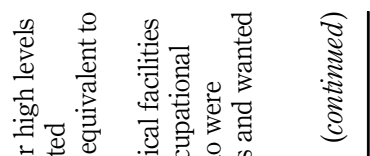

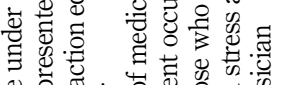

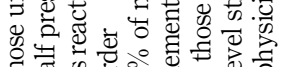

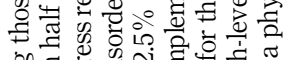
\& 0 选

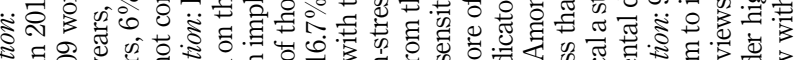

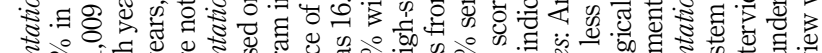

ई०ें

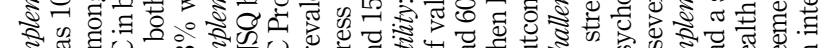

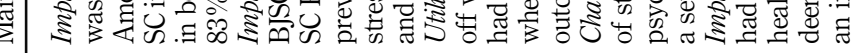
ส

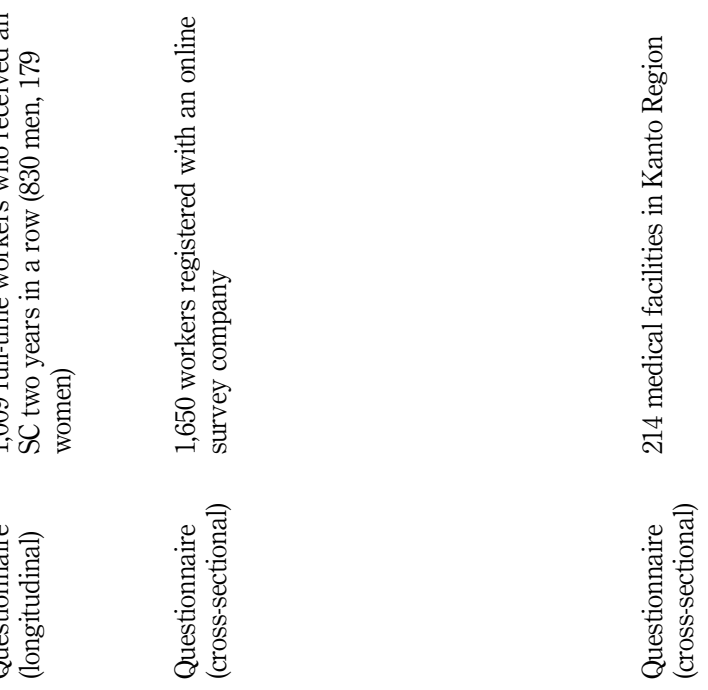

旁

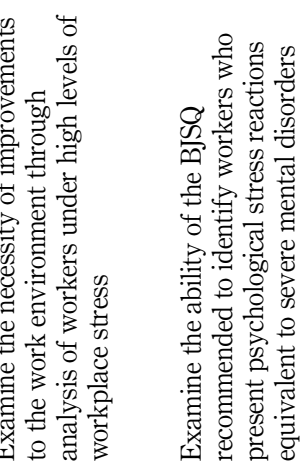

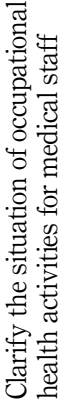

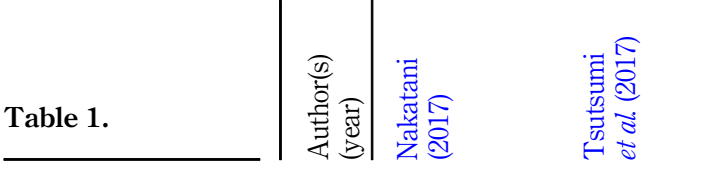

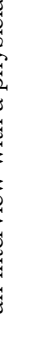




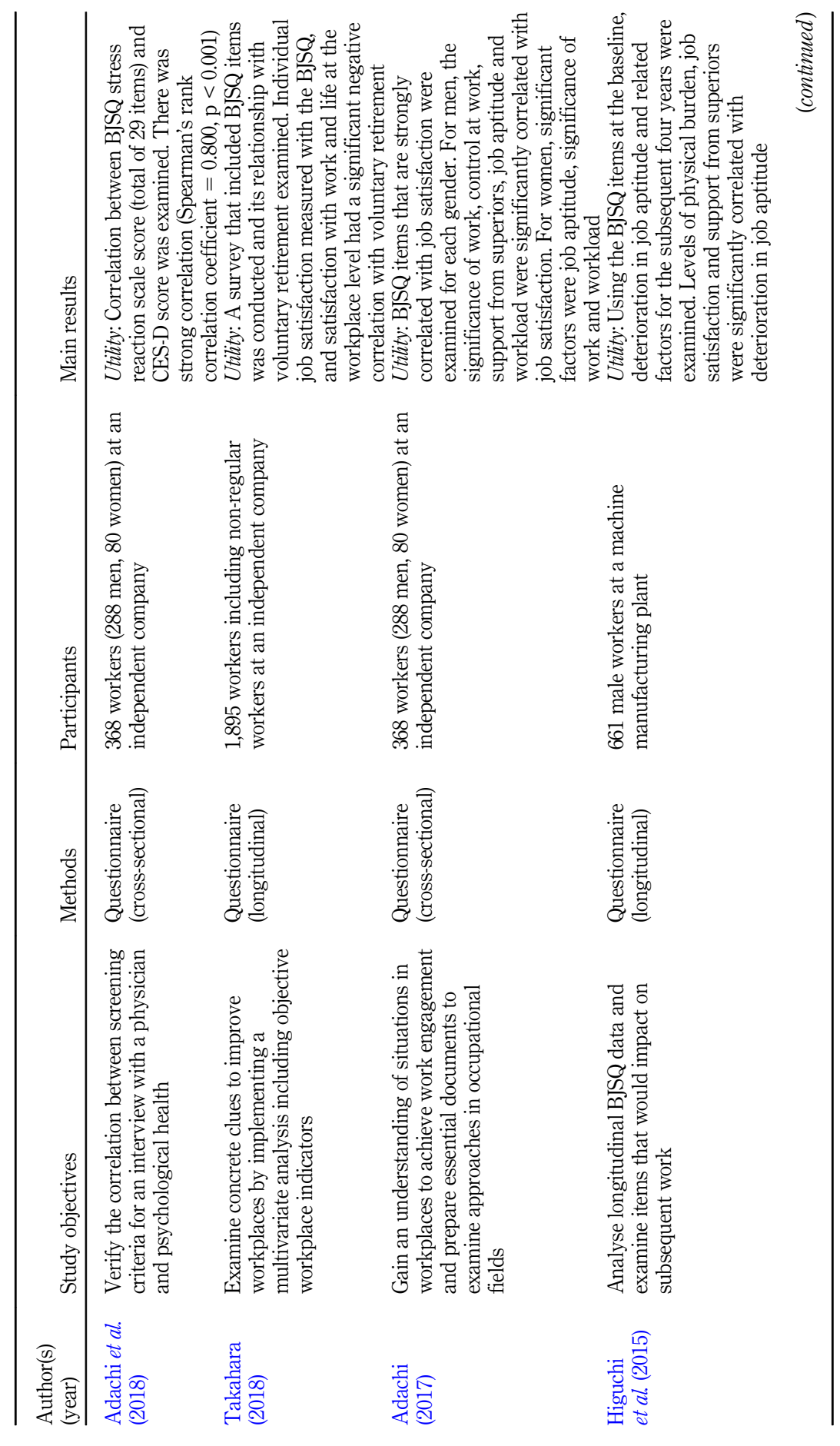

Stress Check Program

657

Table 1. 
IJWHM
13,6

658

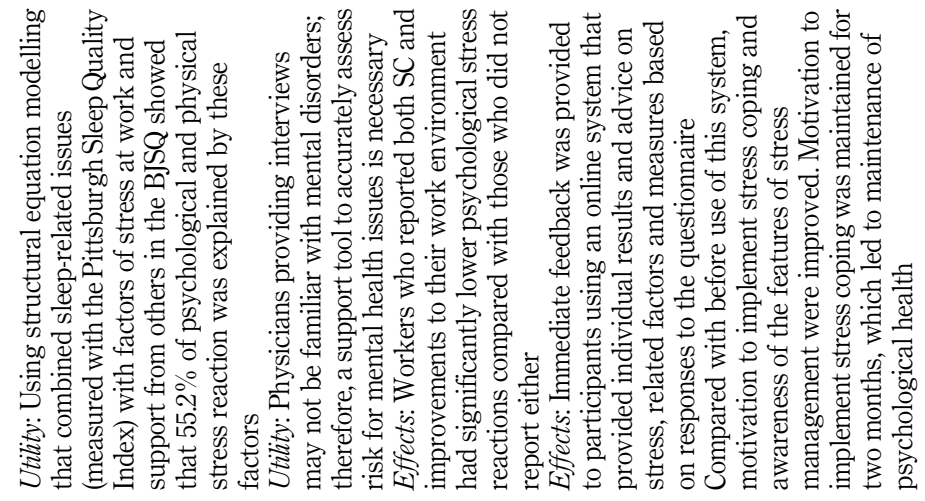


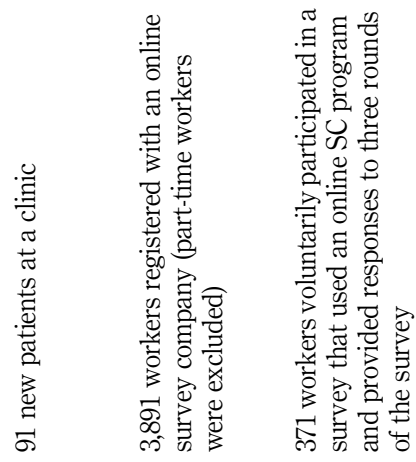

용요

를

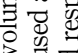

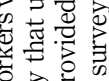

的寻芯艺

告

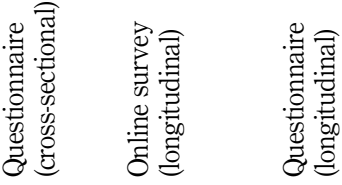

宅

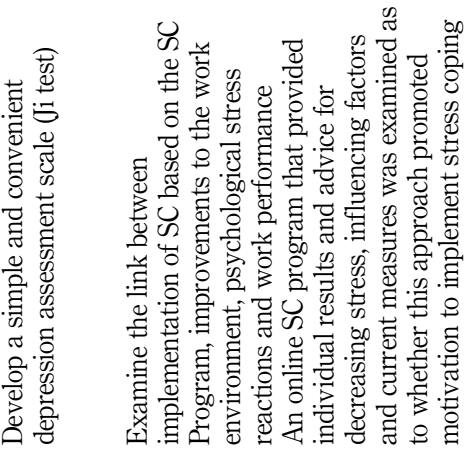

Table 1.

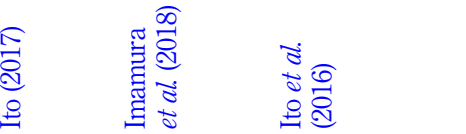




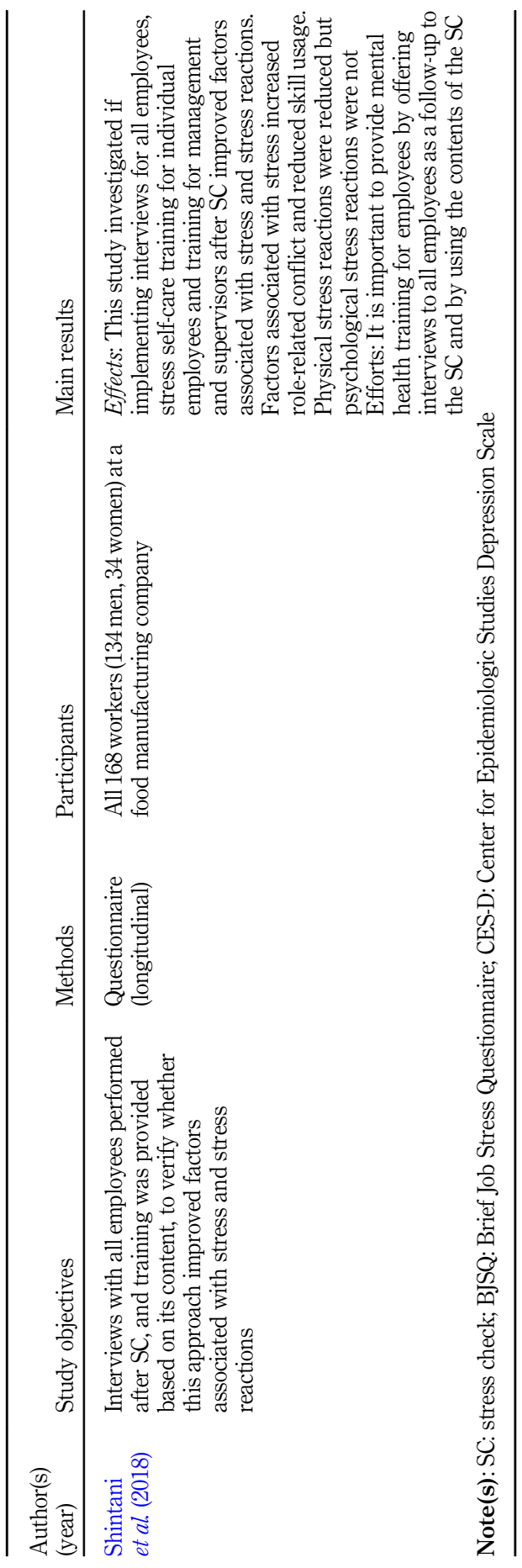

Stress Check

Program

659

Table 1. 
IJWHM 13,6

workplace improvement), and "examination rate", to refer to the proportion of workers who underwent stress checks among those who were expected to do so.

\section{Implementation rate of the Stress Check Program}

Asai et al. (2018) conducted an online survey with 3,891 full-time workers across Japan to clarify the implementation status of the Stress Check Program in its first year. They found that among respondents working at enterprises with $\geq 50$ workers, $52.5 \%$ had received notification of the implementation of the Stress Check Program. Stratified analyses based on respondents' demographics revealed that notification of program implementation was more common among workers aged 40-49 years and those in manufacturing positions. An analysis based on the scale of enterprises showed that larger enterprises had more workers who received notification. That study also reported that $12.1 \%$ of workers at small-scale enterprises had received a notification of the implementation of the Stress Check Program from their employer.

In addition, two reports examined small-scale enterprises. Takeishi et al. (2017) conducted a survey of 38 small-scale enterprises in Saitama Prefecture and reported a low implementation rate of stress checks (13 workplaces, $34 \%$ ). The most common reason for not implementing the Stress Check Program in small-scale enterprises was because they were only obliged to make "reasonable efforts." Saito et al. (2019) examined the implementation rate of stress checks in small-scale enterprises in Aichi Prefecture by dividing them into independent companies $(n=290)$ and branches of companies with multiple locations ( $n=331$; e.g. offices, branches, sales offices). The results showed that the implementation rate of stress checks was 15\% for independent enterprises and $56 \%$ for branches, which clearly showed a difference based on enterprise size. That study also reported that enterprises with mental health staff had significantly higher implementation rates of stress checks than enterprises without mental health staff.

\section{Examination rate of stress checks}

The nation-wide survey by Asai et al. (2018) showed that among workers who were notified of the Stress Check Program, 92.0\% actually underwent stress checks at enterprises with 50 or more workers, and $84.7 \%$ underwent stress checks at small-scale enterprises. Ishimaru et al. (2018) used data for 31,156 workers who received both a stress check from an occupational health agency and a routine health checkup, and they reported that $90.8 \%$ of workers had received a stress check. In terms of the scale of enterprises, stress checks were reported by $91.1 \%$ of workers at enterprises with $\geq 50$ workers and $87.3 \%$ of workers at small-scale enterprises. In addition, that study reported the examination rate varied based on workers' attributes. A higher examination rate was reported among workers aged $\geq 30$ years, those with occupations such as construction, transportation and postal services and those in enterprises with 5-999 workers compared with workers aged 1-29 years, those in manufacturing jobs and those in enterprises with 1-49 workers. However, those in occupations such as medical and welfare services and who worked in enterprises with $\geq 1,000$ employees had significantly lower examination rates compared with those in manufacturing jobs and enterprises with 1-49 workers. In addition, stress checks implemented on dates closer to routine health checkups had higher examination rates.

Muratani (2017) reported the stress check examination rate was $78 \%$ in an academic institution (a university and junior college) with 683 staff. Nakatani (2017) reported that the examination rate of stress checks implemented over two years at corporate groups that included multiple occupations (e.g., sales, manufacturing, and distribution) was $100 \%$ in 2016 and $99.6 \%$ in 2017. However, the examination rate for workers at each workplace was not reported in the two papers that examined small-scale enterprises (Saito et al., 2019; Takeishi et al., 2017). 
Prevalence of workers under high levels of stress

Asai et al. (2018) reported that among workers who received a stress check, the prevalence of workers who were identified as under high levels of stress was $14.2 \%$ in enterprises with $\geq 50$ workers and $14.4 \%$ at small-scale enterprises. Tsutsumi et al. (2017) conducted an online survey involving 1,650 workers. They reported that the prevalence of workers under high levels of stress as determined using the BJSQ (Shimomitsu, 2000) based on the assessment criteria indicated in the Stress Check Program Implementation Manual (Ministry of Health, Labour and Welfare, Japan, 2015) (referred to as the Manual) and according to the Industrial Safety and Health Act was $16.7 \%$ with the 57 -item version and $15.5 \%$ with the 23 -item (short) version. In addition, Tsutsumi et al. (2018) conducted a prospective cohort study with 14,718 workers at a financial service company (7,356 men, 7,362 women) and reported that the prevalence of workers under high levels of stress calculated with similar assessment criteria (57-item version of the BJSQ) was $5.6 \%$ for men and $15.0 \%$ for women. The survey of the academic institution (university and junior college) found that $11 \%$ of staff was under high stress (Muratani, 2017). In addition, the study focussed on stress checks among workers at corporate groups (sales, manufacturing and distribution) concluded that among 1,009 full-time workers who received stress checks in 2016 and $2017,5 \%$ were under high stress in both years, whereas 6\% were under high stress in 2016 and 6\% reported high stress in 2017 (Nakatani, 2017). That study also reported that $83 \%$ of workers were not under high stress in either year.

\section{Implementation rate of interviews with physicians}

Asai et al. (2018) found that among workers who received a stress check, $2.6 \%$ requested an interview with a physician at enterprises with $\geq 50$ workers, whereas no workers made such request at small-scale enterprises. That study also reported that among those who were identified as under high stress, $18.6 \%$ of those at enterprises with $\geq 50$ workers requested physician interviews, whereas no workers small-scale enterprises made such a request.

In this study, workers were asked for the reasons why not they requested an interview with a physician at enterprises. The followings were the reasons that workers with high stress did not see a doctor: did not receive notice, $19 \%$; forgot to request $1 \%$; had no time, $20 \%$; felt no need, $29 \%$; did not know how useful the interview was, $36 \%$; the problem was solved, $1 \%$; did not think they had stress, $3 \%$; thought they could cope with by themselves, $14 \%$; felt no special need because they consulted on a regular basis, $4 \%$; already saw a doctor, $4 \%$; did not want to let the company know the results, $10 \%$; were anxious about the fact that they saw a doctor being introduced to the company, 11\%. Wada et al. (2018) surveyed 214 medical facilities in the Kanto region and examined implementation of interviews with physicians for those with high levels of stress. They found that $92.5 \%$ of medical facilities indicated they had a system ready to implement interviews with occupational physicians for those identified as under high stress that wished to have such a meeting.

\section{Implementation rate of group analysis and work environment improvement}

In the national survey by Asai et al. (2018), 3.3\% of workers who received a stress check reported that their work environment was improved. The survey by Takeishi et al. (2017) that targeted small-scale enterprises found that eight of the 10 companies surveyed $(80 \%)$ indicated that they would "implement" group analysis.

\section{Utility and validity of tools for stress checks}

Eight of the 18 reviewed papers examined the utility and validity of the BJSQ for the Stress Check Program (Table 1). Three papers examined the relationship between BJSQ scores and mental health indicators, three examined the relationship between the BJSQ and work-related factors and two discussed the necessity of supplementary tools.
Stress Check Program

661 
IJWHM 13,6

662

\section{Relationship between BJSQ scores and mental health indicators}

Adachi and Inaba (2018) examined the relationship between scores on the BJSQ stress response scale (total of 29 items) and the Center for Epidemiological Studies-Depression scale (a depression self-assessment scale) in a cross-sectional study involving 368 workers at an enterprise (288 men, 80 women). That study revealed a strong correlation between the scores for the two scales (Spearman's rank correlation coefficient $=0.800, p<0.001$ ).

Tsutsumi et al. (2017) changed the assessment criteria (i.e., the cutoff value) to screen for high stress using the BJSQ as indicated in the Manual (Ministry of Health, Labour and Welfare, Japan, 2015) and examined the screening efficiency of the Kessler Screening Scale for Psychological Distress (Furukawa et al, 2008; Kessler et al., 2002), with a score of 13 or higher (equivalent to a severe mental disorder) being the outcome indicator. The results showed that when the cutoff value (stress responsescore of $\geq 77$ ) in the Manual was used, the prevalence of those with high stress was $16.7 \%$, with sensitivity of $60.5 \%$, specificity of $88.9 \%$, Youden index of 0.504 , positive predictive value of $47.3 \%$ and negative predictive value of $93.8 \%$. The highest screening efficiency (highest Youden index) was observed when the cutoff value was lowered to 65 , where the prevalence of those with high stress increased to $32.3 \%$ and the positive predictive value dropped to $33.0 \%$.

Similarly, Tsutsumi et al. (2018) examined the relationship between presence/absence of high stress at baseline (determined based on the assessment criteria in the Manual (Ministry of Health, Labour and Welfare, Japan, 2015) and long-term sick leave of $\geq 1$ month during the following year (obtained from human resources data) using a Cox proportional hazards model. The results showed that compared with those who were not under high stress, those with high stress had a long-term sick leave risk due to subsequent mental health issues. The hazard ratios (adjusted for age, years of work, occupation, position, and receiving an interview with occupational health staff after the stress check) were 8.68 for men and 3.67 for women. The equivalent population-attributable risk proportion was $30.1 \%$ for men and $25.6 \%$ for women.

\section{Relationship between BJSQ scores and work-related factors}

Takahara (2018) conducted a survey that included items from the BJSQ with 1,895 temporary workers from a single company and examined the relationship between scores for these items and workers' voluntary retirement. They found that personal-level job satisfaction, workplace-level satisfaction and life satisfaction, as measured by the BJSQ, had a significant negative correlation with voluntary retirement.

Adachi (2017) examined BJSQ items that were strongly related to job satisfaction for 368 workers at a single company ( 288 men, 80 women) based on sex. The results showed that for men, factors that were significantly correlated with job satisfaction were the significance of work, control at work, support from superiors, aptitude in work and the amount of work. For women, aptitude at work, significance of work and the amount of work were significantly correlated with job satisfaction.

Higuchi et al. (2015) used BJSQ items at a baseline assessment for 661 male workers at a machine manufacturing factory to examine factors related to deterioration in respondents' job adaptability in the subsequent four years. They found that levels of physical burden, job satisfaction and support from superiors were significantly related to deterioration in job adaptability.

\section{Necessity of supplementary tools}

Shimura et al. (2018) used structural equation modelling, in which sleep-related issues (identified with the Pittsburgh Sleep Quality Index) were added to factors of stress and support at work drawn from the BJSQ. They showed that $55.2 \%$ of psychological and 
physical stress could be explained through these factors. Those authors argued for the importance of also addressing sleep-related issues in stress checks. Ito (2017) noted that because the physicians that conduct interviews with those under high levels of work stress are not necessarily familiar with mental disorders, a support tool to accurately evaluate the risk for mental health issues is necessary. Therefore, that study proposed the use of a depression screening test (Ji test) that could be easily used in the Stress Check Program.

\section{Effects of the Stress Check Program}

Among the 18 papers reviewed, three examined the effects of the Stress Check Program (Table 1). One paper examined the effects of improvements in the work environment, one examined the effect of the method by which the stress check results were shared with individuals and the last paper examined the effects of other combined approaches.

Imamura et al. (2018) examined the links between implementation of improvements to the work environment through the Stress Check Program, stress responses and work performance. That study included data for 3,891 full-time workers that completed surveys before and after the Stress Check Program (November 2015 and February 2016) (the same subjects as used in the national survey by Asai et al. (2018)). A follow-up survey was conducted one year later, in which participants were interviewed about to whether they received a stress check at their workplace and if there had been any improvements to their work environment. Participants were divided into groups based on whether they had completed stress checks and experienced work environment improvements: "neither" $(53.9 \%)$ ), "stress check only" (40.5\%), "improvement to work environment only" $(3.0 \%)$ and "both" (2.6\%). Possible differences in changes to psychological stress responses and work performance scores were examined. The "both" group had significantly lower stress responses compared with the "neither" group. Imamura et al. (2018) concluded that implementation of the stress check as mandated by the Stress Check Program alone may not be effective in reducing the stress responses of workers and may be more effective in combination with improvements to the work environment.

In terms of sharing the stress check results with workers, Ito et al. (2016) reported on sharing the results of a questionnaire that involved 371 workers at an information technology (IT) company using an Internet-based system. Respondents' stress status, related factors, individual stress management results and related advice were immediately provided by the system based on their answers to a questionnaire. That study showed that when the stress check results were conveyed to respondents using this system, respondents were more aware of the characteristics of stress management and more motivated to implement measures compared with before the intervention. The desire to implement measures continued for two months, and this maintained motivation impacted the maintenance of psychological health. A reason for this result may be that it was effective to have information in the individual report such as: the importance of having repertoires of measures for coping with stress on a daily basis, meaning multiple measures could be used as appropriate when individuals faced various stress-related factors and stressful situations; advice on how changes in mood and perspective could be useful in reducing work-related stress and specific examples that could be incorporated to everyday situations.

In another combined approach, Shintani et al. (2018) examined improvements in stressrelated factors and stress responses after implementing the stress check following several strategies: interviewing all workers, providing stress self-care training for individual workers and providing training for managers and supervisors. Participants were workers at a food manufacturing company (168 total: 134 men, 34 women). In terms of stress-related factors, they reported role-related conflicts increased and skill use declined. With regard to stress responses, there was improvement in physical stress responses but no improvement in
Stress Check Program

663 
IJWHM 13,6 psychological stress responses. The reason for the lack of improvement in stress-related factors may have been related to insufficient sorting of detailed tasks, which could have led to inefficient use of workers' skills.

\section{Discussion}

\section{Implementation of the Stress Check Program}

This review showed the implementation rate of the Stress Check Program was $53 \%$ at enterprises with $\geq 50$ workers and $12-56 \%$ at small-scale enterprises. However, the national survey by Asai et al. (2018) was conducted in the early December of 2016, and numbers from any subsequent surveys were not included. Therefore, implementation rates for the following three years (2017-2019) may be expected to be higher (Asai et al., 2018). According to the report on the implementation of the Stress Check Program prepared by the Ministry of Health, Labour and Welfare based on the reports submitted by enterprises to labour standards inspection offices (2017) (Ministry of Health, Labour and Welfare, Japan, 2017a), the Stress Check Program was implemented at $82.9 \%$ of enterprises in which it was mandated. In a survey that included workers at small-scale enterprises, which are not legally mandated to implement the Stress Check Program, implementation rates tended to be underestimated (Imamura and Kawakami, 2017); therefore, caution is needed when evaluating the program implementation rate in small-scale enterprises. However, implementation rates tended to below in small-scale enterprises, especially small-scale independent enterprises (Saito et al., 2019). The official report on the Stress Check Program implementation (2017) (Ministry of Health, Labour and Welfare, Japan, 2017a) presented implementation rates for each type of enterprise, which were particularly low in the hospitality and entertainment, cleaning and animal husbandry areas.

Within the scope of the survey, the examination rate of the stress check exceeded $90 \%$ in workplaces with $\geq 50$ or more workers and $80 \%$ in workplaces with $<50$ workers. In terms of occupation, the examination rate was particularly low for medical workers (Saito et al., 2019) and educators (Muratani, 2017).

Although stress levels may depend on the individual workplace, $10-15 \%$ of workers on average were identified as under high levels of stress. However, only a limited number of workers received an interview with a physician. According to the 2017 Ministry of Health, Labour and Welfare report (Ministry of Health, Labour and Welfare, Japan, 2017a), among all those examined (examination rate of $78.0 \%$ ), only $0.6 \%$ received an interview with a physician.

According to the survey by (Asai et al., 2018), 3.3\% of workers that received a stress check reported that their work environment had improved (Asai et al., 2018). If workers were not involved in these changes to the work environment, it is likely that many workers may be unaware of improvements to their work environment, which could have resulted in underestimation of workplace improvements. In a subsequent national survey (Ministry of Health, Labour and Welfare, Japan, 2017b), the implementation rate was reported as $69 \%$ for enterprises with $\geq 50$ workers and $58.3 \%$ overall. In the same survey, more than $70 \%$ of workplaces conducted group analyses using the stress check results, but specific details are unknown. In the survey of workplaces across Japan conducted by Kawakami (2012), the proportion of workplaces where any measures to improve the work environment were implemented after the stress checks increased from $37.0 \%$ in 2016 to $44.2 \%$ in 2017 . However, many of these measures were "reporting and providing explanations to management," whereas only $4-7.5 \%$ of workplaces implemented "participatory improvements to the work environment" that were considered effective in reducing workers' stress.

Implementation rates, examination rates and use of results for group analysis (including those separated by the scale of enterprises and industry) are important indicators in the distribution of 
the Stress Check Program, and a further detailed survey is necessary. The reviewed literature showed that to further promote the Stress Check Program among small-scale enterprises, it is important to increase implementation efforts, such as tackling projects by appointing someone in charge of promoting mental health (Saito et al.,2019) and implementing a stress check with routine health checkups (Ishimaru et al., 2018). The literature also showed the necessity of managing the financial burden and other complexities, such as privacy in implementing stress checks, while making sure that the subsidy system is well known (Takeishi et al., 2017).

Utility and validity of tools used for stress checks

The BJSQ has a certain level of validity for mental health-related outcomes (Adachi and Inaba, 2018; Tsutsumi et al., 2017; Tsutsumi et al., 2018) and work-related outcomes (Adachi, 2017; Higuchi et al., 2015; Takahara, 2018). Specifically, the fact that a high level of stress has over a $25 \%$ population-attributable risk for mental health-related sick leave (Tsutsumi et al., 2018) indicated that the BJSQ is a valid measure to identify high-risk groups for mental health issues. Although there is no evidence since the Stress Check Program started, the "Job Stress Assessment Diagram" that was prepared based on BJSQ responses to visualize health risks associated with job stressors has shown positive effects on the improvement of work environments (Kobayashi et al., 2008; Tsutsumi et al., 2009), and was used as a tool for group analysis in many studies.

Overall, the effectiveness of the Stress Check Program has not been shown for stressrelated factors that are not identified by the Job Stress Assessment Diagram (i.e. factors other than workload, control at work and support at work). It is therefore necessary to examine whether unused items could be useful to understand high stress and inform measures to improve work environments. Although they may differ between industries, "subjective physical burden," "job satisfaction," "significance of work," and "aptitude at work" (for which the link with work-related factors has been shown) may be items that could provide useful information for stress-related measures (Adachi, 2017; Higuchi et al., 2015; Takahara, 2018). However, further empirical findings are needed.

Screening of those under high levels of stress by the BJSQ using assessment criteria as specified in the Manual (Ministry of Health, Labour and Welfare, Japan, 2015) is considered useful (Tsutsumi et al., 2017). However, among those identified as under high stress, less than half presented psychological stress responses equivalent to a severe mental disorder; therefore the ability to screen individuals during implementation of the Stress Check Program has limitations. It is necessary to verify if it is useful to consider sleep-related issues (Shimura et al., 2018), combining the BJSQ with supplementary tests (e.g. an assessment scale for depression (Ito, 2017)) and other related tools.

\section{Effects of the stress check program}

Reducing the risk for mental health issues through conducting routine surveys of workers and sharing the results. A previous randomized controlled trial did not support the idea that providing feedback from stress surveys to workers reduced the risk for mental health issues (Kawakami et al., 1999; Ketelaar et al., 2013). The present review found one study that showed that sharing individual results and providing advice to improve issues using an IT-based system improved awareness of stress management and motivation to implement measures (Ito et al., 2016). However, that study was a before-and-after trial conducted without controls. Whether the immediacy of feedback from a stress check and the validity of advice can contribute to its effectiveness need to be verified in further studies.

Screening of those under high levels of stress and interviews with physicians. No available study investigated the effect of interviews with physicians for those under high levels of stress following a stress check. There are few studies worldwide that have shown the
Stress Check Program

665 
IJWHM 13,6

666

effectiveness of screening for mental disorders such as depression following stress checks. Wang et al. (2007) reported that intensive care by trained social workers and experts following screening was effective (Wang et al., 2007). Considering the low implementation rates of interviews with physicians in the Stress Check Program in Japan, interviews with physicians are unlikely to be effective in the present system that targets those under high levels of stress.

It is difficult to demonstrate the effectiveness of the secondary preventative functions of the Stress Check Program within current mandatory frameworks, but measures for managing those under high levels of stress at risk for mental health-related sick leave are necessary. The studies we reviewed recommended tools such as, self-care using existing points of contact with workers, preliminary interviews with public health nurses (Masuzawa et al., 2018), frameworks for ex-post actions that could be passed onto experts and the creation of a simple manual that includes the previous options. In addition, re-examination of procedures for interviews with physicians including requests filed by workers was proposed to create a system where stress-related consultation was easy for workers.

Interviews with workers and self-care training related to the Stress Check Program (Shintani et al., 2018) could be designed to fit the capacity of workplaces and occupational health staff within the framework of comprehensive mental health measures. The cost of measures for workplace stress is also being examined, which can be used as a further reference in reviewing the system (Yoshimura et al., 2013).

Reducing psychological stress responses through improvement of the work environment based on group analysis (including education for management and supervisors). A combination of a stress checks and improvements in the work environment may reduce workers' psychological stress responses (Imamura et al., 2018). As the Stress Check Program started, no study has verified the effect of the program on workers' mental health by using group analysis of stress check results. However, some studies verified the effects of improvements in the work environment implemented based on the stress check results using the occupational stress model within a similar framework (Egan et al., 2007; Lamontagne et al., 2005; Montano et al., 2014). The present results are consistent with these reports.

\section{What the relevance of the stress check program is as implemented in Japan to other countries}

The Japanese Stress Check Program focuses on prevention of mental health problems by combining an annual stress survey that aims to decrease the risk for mental health problems by increasing workers' awareness of their own stress and allowing group analysis to improve the workplace psychosocial environment. The major strategy for improving worker mental health in European countries is risk assessment and management of psychosocial factors at work (e.g. Psychosocial Risk Management Excellence Framework: PRIMA-EF) (International Labour Organization, 2012; Leka et al., 2011). This approach focuses on the psychosocial work environment. The ordinal procedure for the psychosocial risk assessment at work is conducted by using an anonymous survey, and the report is summarized based on the group. Compared with national policies and programs to prevent occupational stress conducted in other countries (Brookes et al., 2013; Daniels et al., 2012; Mackay et al., 2004; Malachowski et al., 2017), Japan's program is unique in that individual workers are identified (for screening purposes) and group analysis is not mandatory.

It may reflect a culture of paternalistic approach of Japanese occupational health system, in which employers are expected to protect employees' health and welfare (Kawakami and Tsutsumi, 2016). Such individualized approach could be easily adopted by the countries with similar cultural backgrounds and/or occupational health systems, such as general health examination at workplace (Kang et al., 2017). It is also interesting to see the effects of the Stress Check System in the countries sharing common occupational health issues (Tsutsumi, 2019). 
However, the effect of the program needs to wait for the future evaluation on the longer-term impact of the program.
Stress Check Program

\section{Conclusions}

The aim of the 13th Occupational Safety and Health Program (2018-2022) (Japan Ministry of Health, Labour and Welfare) is to increase the proportion of workplaces that perform group analysis using the results of stress checks and utilize the results to $60 \%$ or higher (Ministry of Health, Labourand Welfare, Japan, 2018). The results of group analysis can be used at various levels, such as comparisons of overall enterprises with the national average, comparisons between departments and improvements in the work environment based on the results. As discussed earlier, implementation of improvements in the work environment as part of the Stress Check Program was observed in a number of workplaces; however, few workplaces had made improvements based on stress check results. Improvements in the work environment that are linked with the Stress Check Program need to be further promoted. Further efforts are needed to narrow the gap between evidence and implementation, including improving guidance manuals and introducing different methods based on successful cases to increase the on-site implementation potential of the Stress Check Program.

The Japanese Stress Check Program contrasts with risk management of psychosocial factors at work as a strategy for improving workers' mental health proposed by international bodies such as the World Health Organization and the International Labor Organization. These strategies target the psychosocial work environment rather than psychosocial stress among individual workers. Although the effectiveness of the Japanese program needs further evaluation, future developments of the program would provide insight for national policies on psychosocial risks/psychosocial stress at work.

\section{References}

Adachi, K. (2017), "Examination of factors necessary to achieve work engagement from a viewpoint of job satisfaction", The Japanese Psychiatric Nursing Society, Vol. 60, pp. 362-366, (in Japanese).

Adachi, K. and Inaba, R. (2018), "Verification of the correlation of criteria for identifying highly stress individuals based on the sum of psychological and physical stress reaction scores of the brief job stress questionnaire with the Center for epidemiologic studies depression scale score", Japanese Journal of Occupational Medicine and Traumatology, Vol. 66, pp. 33-39, (in Japanese).

Asai, Y., Imamura, K., Tsutsumi, A., Shimazu, A., Inoue, A., Hiro, H., Odagiri, Y., Yoshikawa, T., Yoshikawa, E. and Kawakami, N. (2018), "Implementation, usefulness and concerns of the stress check program in the first year: an internet survey of employees", Job Stress Research, Vol. 25, pp. 257-271, (in Japanese).

Brookes, K., Limbert, C., Deacy, C., O’Reilly, A., Scott, S. and Thirlaway, K. (2013), "Systematic review: work-related stress and the HSE management standards", Occupational Medicine (Lond), Vol. 63 No. 7, pp. 463-472.

Daniels, K., Karanika-Murray, M., Mellor, N. and van Veldhoven, M.J.P.M. (2012), "Moving policy and practice forward: beyond prescriptions for job characteristics", in Biron, C., Karanika-Murray, M. and Cooper, C. (Eds), Improving Organizational Interventions for Stress and Well-Being. Addressing Process and Context, Routledge/Psychology Press, Hove, pp. 313-332.

Egan, M., Bambra, C., Thomas, S., Petticrew, M., Whitehead, M. and Thomson, H. (2007), "The psychosocial and health effects of workplace reorganisation. 1. a systematic review of organisational-level interventions that aim to increase employee control", Journal of Epidemiology and Community Health, Vol. 61, pp. 945-954.

Furukawa, T.A., Kawakami, N., Saitoh, M., Ono, Y., Nakane, Y., Nakamura, Y., Tachimori, H., Iwata, N., Uda, H., Nakane, H., Watanabe, M., Naganuma, Y., Hata, Y., Kobayashi, M., Miyake, Y., 
IJWHM 13,6

668

Takeshima, T. and Kikkawa, T. (2008), "The performance of the Japanese version of the K6 and K10 in the World mental health survey Japan", International Journal of Methods in Psychiatric Research, Vol. 17, pp. 152-158.

Higuch, Y., Izumi, H., Fujiki, M., Akatsuki, S. and Kumashiro, M. (2015), "Noteworthy items in stress check at work: prediction of work ability deterioration in four years follow-up study", Journal of Ergonomics in Occupational Safety and Health, Vol. 17, pp. 29-32, (in Japanese).

Imamura, K. and Kawakami, N. (2017), "Current situation, issues, and evaluation of effectiveness in the first year of stress check program in Japan”, Journal of Clinical and Experimental Medicine, Vol. 263, pp. 230-233, (in Japanese).

Imamura, K., Asai, Y., Watanabe, K., Tsutsumi, A., Shimazu, A., Inoue, A., Hiro, H., Odagiri, Y., Yoshikawa, T., Yoshikawa, E. and Kawakami, N. (2018), "Effect of the National Stress Check Program on mental health among workers in Japan: a 1-year retrospective cohort study", Journal of Occupational Health, Vol. 60, pp. 298-306.

International Labour Organization (2012), Stress Prevention at Work Checkpoints: Practical Improvements for Stress Prevention in the Workplace, available at: http://www.ilo.org/ safework/info/instr/WCMS_177108/lang-es/index.htm.

Ishimaru, T., Hattori, M., Nagata, M., Kuwahara, K., Watanabe, S. and Mori, K. (2018), "Factors associated with stress check attendance: possible effect of timing of annual health examination", Nihon Eiseigaku Zasshi, Vol. 73, pp. 235-240, (in Japanese).

Ito, H. (2017), "Development of self rating questionnaire for depression - Ji test: first report: - statistical analysis and prospects for the stress check program", Japanese Journal of Psychosomatic Medicine, Vol. 57, pp. 944-954, (in Japanese).

Ito, S., Yamamoto, H. and Tsuda, A. (2016), "Effects of the "MENTAL-ROSA II" web-based stress check system on promoting mental health self-care among Japanese employees", Japanese Journal of Occupational Medicine and Traumatology, Vol. 64, pp. 54-65, (in Japanese).

Kang, Y.J., Myong, J.P., Eom, H., Choi, B., Park, J.H. and EA, L.K. (2017), "The current condition of the workers' general health examination in South Korea: a retrospective study", Ann Occup Environ Med, Vol. 29, p. 6.

Kawakami, N. (2012), A Study on the Prevention of Mental Health Disorders of Workers and the Effect of Improving the Work Environment by the Stress Check System, Ministry of Health, Labor and Welfare Health and Labor Sciences Research Grant Subsidy, Occupational Health and Safety Research Project, Japan.

Kawakami, N. and Tsutsumi, A. (2016), "The Stress Check Program: a new national policy for monitoring and screening psychosocial stress in the workplace in Japan”, Journal of Occupational Health, Vol. 58, pp. 1-6.

Kawakami, N., Haratani, T., Iwata, N., Imanaka, Y., Murata, K. and Araki, S. (1999), "Effects of mailed advice on stress reduction among employees in Japan: a randomized controlled trial", Industrial Health, Vol. 37, pp. 237-242.

Kessler, R.C., Andrews, G., Colpe, L.J., Hiripi, E., Mroczek, D.K., Normand, S.L., Walters, E.E. and Zaslavsky, A.M. (2002), "Short screening scales to monitor population prevalences and trends in non-specific psychological distress”, Psychological Medicine, Vol. 32, pp. 959-976.

Ketelaar, S.M., Nieuwenhuijsen, K., Gärtner, F.R., Bolier, L., Smeets, O. and Sluiter, J.K. (2013), "Effect of an E-mental health approach to workers' health surveillance versus control group on work functioning of hospital employees: a cluster-RCT", PLoS One, Vol. 8, e72546.

Kobayashi, Y., Kaneyoshi, A., Yokota, A. and Kawakami, N. (2008), "Effects of a worker participatory program for improving work environments on job stressors and mental health among workers: a controlled trial", Journal of Occupational Health, Vol. 50 No. 6, pp. 455-470.

Lamontagne, A.D., Keegel, T., Louie, A.M., Ostry, A. and Lamdsbergis, P.A. (2005), "A systematic review of the job-stress intervention evaluation literature, 1990. 2005”, International Journal of Occupational and Environmental Health, Vol. 13, pp. 268-280. 
Leka, S., Jain, A., Cox, T. and Kortum, E. (2011), "The development of the European framework for psychosocial risk management: PRIMA-EF", Journal of Occupational Health, Vol. 53 No. 2, pp. 137-143.

Mackay, C.J., Cousins, R., Kelly, P.J., Lee, S. and McCaig, R.H. (2004), "Management standards and work-related stress in the UK: policy background and science", Work Stress, Vol. 18 No. 2, pp. 91-112.

Malachowski, C., Kirsh, B. and McEachen, E. (2017), “The sociopolitical context of Canada's national standard for psychological health and safety in the workplace: navigating policy implementation”, Healthcare Policy / Politiques de sante, Vol. 12 No. 4, pp. 10-17.

Masuzawa, K., Kobayashi, H., Sano, M., Tsunoda, H., Tanaka, K. and Noji, A. (2018), "Study of assessment items and measurement processes for the ongoing health interview after the stress check by the occupational health nurses", Journal of Japan Academy of Occupational Health Nursing, Vol. 5, pp. 1-7, (in Japanese).

Ministry of Health (2015), Labour and Welfare, Japan, available at: http://www.mhlw.go.jp/bunya/ roudoukijun/anzeneisei12/ (accessed 17 April 2019).

Ministry of Health (2017a), Labour and Welfare, Japan, available at: https://www.mhlw.go.jp/stf/ houdou/0000172107.htm (accessed 14 June 2019).

Ministry of Health, Labour and Welfare. Japan (2017b), Industrial Safety and Health Survey, Japan, 2017 available at: https://www.mhlw.go.jp/toukei/list/h29-46-50.html (accessed 14 June 2019).

Ministry of Health, Labour and Welfare, Japan (2018), The 13th Occupational Safety and Health Program (2018 to 2022), available at: https://www.mhlw.go.jp/file/06-Seisakujouhou-11200000Roudoukijunkyoku/0000197927.pdf.

Montano, D., Hoven, H. and Siegrist, J. (2014), "Effects of organisational-level interventions at work on employees' health: a systematic review", BMC Public Health, Vol. 14, p. 135.

Muratani, H. (2017), "The first time stress check for the employee of Nakamura Sangyo Gakuen", Studies in Health and Sports Science, Vol. 19, pp. 19-27, (in Japanese).

Nakatani, M. (2017), "Results of the 2016-2017 stress check program for high-stress workers indicate that the work environment needs to be improved”, Matsushita Medical Journal, Vol. 56, pp. 72-81, (in Japanese).

Saito, M., Nakamoto, K., Wada, H., Nishitani, N. and Yamamoto, M. (2019), "A study on the implementation of stress checks to small-scale workplaces and the taking is effective to promote the implementation”, Sangyo Eiseigaku Zasshi, Vol. 61, pp. 1-8, (in Japanese).

Shimomitsu, T. (2000), "The final development of the Brief Job Stress Questionnaire mainly used for assessment of individuals, the Ministry of Labour sponsored grant for the prevention of workrelated illness", The 1999 Research Report, pp. 117-164.

Shimura, A., Tanaka, T., Misaki, S., Sugiura, K., Oono, K., Hayashida, T., Komada, Y., Takaesu, Y., Furui, Y. and Inoue, T. (2018), "Assessment of the effect of sleep disturbance and occupational stress on the stress response", SeishinIgaku (Clinical Psychiatry), Vol. 60, pp. 783-791, (in Japanese).

Shintani, N., Nagaoka, H. and Shintani, M. (2018), "Effects of a follow-up after an occupational stress check: results of carrying out interviews and stress training with all staff members", Journal of Ergonomics in Occupational Safety and Health, Vol. 20, pp. 25-28, (in Japanese).

Takahara, R. (2018), "Survival analysis using the Stress Check data to predict employee turnover", Japanese Journal of Interpersonal and Social Psychology, Vol. 18, pp. 1-9, (in Japanese).

Takeishi, Y., Matsumoto, K., Matsumoto, M. and Suda, T. (2017), "Stress checks at small-scale businesses”, The Journal of the Saitama Medical Society, Vol. 52, pp. $63-68$ (in Japanese).

Tsutsumi, A., Nagami, M., Yoshikawa, T., Kogi, K. and Kawakami, N. (2009), "Participatory intervention for workplace improvements on mental health and job performance among bluecollar workers: a cluster randomized controlled trial”, Journal of Occupational and Environmental Medicine, Vol. 51 No. 5, pp. 554-563. 
IJWHM 13,6

Tsutsumi, A. (2016), "Work stress and health: the case of Japan", in Siegrist, J. and Wahrendorf, M. (Eds), Work Stress and Health in a Globalized Economy. Aligning Perspectives on Health, Safety and Well-Being, Springer, Cham.

Tsutsumi, A. (2019), "Preventing overwork-related deaths and disorders-needs of continuous and multi-faceted efforts", Journal of Occupational Health, Vol. 61, pp. 265-266.

Tsutsumi, A., Inoue, A. and Eguchi, H. (2017), "How accurately does the brief job stress questionnaire identify workers with or without potential psychological distress?", Journal of Occupational Health, Vol. 59, pp. 356-360.

Tsutsumi, A., Shimazu, A., Eguchi, H., Inoue, A. and Kawakami, N. (2018), "A Japanese Stress check program screening tool predicts worker long-term sickness absence: a prospective study", Journal of Occupational Health, Vol. 60 No. 1, pp. 55-63.

Wada, K., Ogawa, M. and Komori, T. (2018), "Study on occupational health activities in medical facilities in the Kanto region (2017)", The Journal of the Japan Medical Association, Vol. 146, pp. 2536-2541, (in Japanese).

Wang, P.S., Simon, G.E., Avorn, J., Azocar, F., Ludman, E.J., McCulloch, J., Petukhova, M.Z. and Kessler, R.C. (2007), "Telephone screening, outreach, and care management for depressed workers and impact on clinical and work productivity outcomes: a randomized controlled trial", JAMA, Vol. 298, pp. 1401-1411.

Yoshimura, K., Kawakami, N., Tsutsumi, A., Inoue, A., Kobayashi, Y., Takeuchi, A. and Fukuda, T. (2013), "Cost-benefit analysis of primary prevention programs for mental health at the workplace in Japan", Sangyo EiseigakuZasshi, Vol. 55, pp. 11-24, (in Japanese).

\section{Corresponding author}

Akizumi Tsutsumi can be contacted at: akizumi@kitasato-u.ac.jp

For instructions on how to order reprints of this article, please visit our website:

www.emeraldgrouppublishing.com/licensing/reprints.htm

Or contact us for further details: permissions@emeraldinsight.com 